\title{
The use of acarbose inhibition in the measurement of acid alpha-glucosidase activity in blood lymphocytes for the diagnosis of Pompe disease
}

\author{
Rhona M. Jack, $P h D^{1}$, Cindy Gordon, $B S^{1}$, C. R. Scott, $M D^{3}$, Priya S. Kishnani, $M D^{2}$, and Deeksha Bali, $P h D^{2}$
}

\begin{abstract}
Purpose: Acid alpha-glucosidase is present in various tissues, including blood cells. Historically, enzyme measurement in cultured fibroblasts, or muscle, has been the gold standard to confirm a diagnosis of Pompe disease, due to the possibility of alternate isoenzyme activity masking disease in white cell assays. Enzyme measurement in an isolated lymphocyte population with acarbose, an inhibitor of neutral alpha-glucosidase, has greatly improved the sensitivity and specificity of the test in blood cells allowing for more rapid laboratory testing for Pompe disease. Methods: An assay for acid alpha-glucosidase was performed with and without inhibitor in lymphocytes from 14 patients with a clinical suspicion of infantile Pompe disease. Concurrent testing was performed in fibroblasts in an independent laboratory. Results: Thirteen of 14 patients demonstrated a clear deficiency in lymphocytes with acarbose inhibition. One patient was indeterminate, although below normal activity, suggesting the need for confirmatory testing. Tissue enzyme activity in all was consistent with infantile Pompe disease, and corroborated enzyme activity seen in lymphocytes. There were no false positives for disease, making the positive predictive value of lymphocyte enzyme testing 100\%. Conclusion: Enzyme assay using acarbose as an inhibitor, can be performed in isolated lymphocytes for rapid diagnosis of infantile Pompe disease. Genet Med 2006:8(5):307-312.
\end{abstract}

Key Words: pompe disease, pompe enzyme diagnosis, acid-alpha-glucosidase, lymphocytes, GAA

Pompe disease, or glycogen storage disease type II, is an autosomal recessive disorder caused by the deficiency of lysosomal acid alpha-glucosidase (GAA EC 3.2.1.3) activity. The gene that encodes acid alpha-glucosidase has been mapped to chromosome 17q25. Classic infantile Pompe disease presents within the first months of life with hypertrophic cardiomyopathy, hypotonia, generalized muscle weakness, macroglossia, hepatomegaly, and storage of glycogen within all tissues. ${ }^{1,2,3}$ Infantile Pompe disease typically progresses rapidly to death in the first year of life, primarily due to cardio-respiratory failure or respiratory infection. ${ }^{2,4,5}$

Late-onset forms (juvenile- and adult-onset) of Pompe disease also exist, with symptoms manifesting primarily as muscle weakness. These late-onset forms of disease retain partial enzyme activity in fibroblasts and muscle. ${ }^{1}$ The combined incidence of the different forms of Pompe disease is approximately $1: 40,000.6,7$

\footnotetext{
From the ${ }^{1}$ Department of Laboratories, Children's Hospital and Regional Medical Center, Seattle, WA; ${ }^{2}$ Department of Pediatrics, Division of Medical Genetics, Duke University Medical Center, Durham, NC; ${ }^{3}$ University of Washington/Children's Hospital and Regional Medical Center, Department of Pediatrics, Seattle, WA.

Rhona Jack, PhD, Department of Laboratories, Children's Hospital and Regional Medical Center, 4800 Sand Point Way NE, Seattle, WA, 98105.

Submitted for publication January $7,2006$.

Accepted for publication February 27, 2006
}

DOI: 10.1097/01.gim.0000217785.19262.9e
Clinical suspicion of disease is raised by presenting signs and symptoms. Serum creatine kinase (CK) elevation is a sensitive although non-specific marker for Pompe disease, with greatest elevations seen in infantile-onset patients. Approximately $95 \%$ of late-onset patients have an elevated CK. Serum enzymes such as aspartate aminotransferase (AST), alanine aminotransferase (ALT), or lactate dehydrogenase (LDH) may be elevated as well. Patients presenting in infancy have cardiomegaly on chest $\mathrm{x}$-ray. Short PR intervals with tall and broad QRS complexes are characteristic findings on EKG. Echocardiography may reveal thickening of both ventricles and/or the intra-ventricular septum and/or left ventricular outflow tract obstruction. Muscle biopsy is often done in late-onset cases as part of the work-up for a myopathy. Lysosomal storage of glycogen is noted on histology; the caveat is that a diagnosis of Pompe disease can be missed since muscle histology and glycogen content can vary depending on the site of the muscle biopsy. Once a constellation of symptoms and laboratory findings suggestive of Pompe disease is noted, the confirmatory step is a GAA enzyme assay. This assay is usually done in muscle or cultured skin fibroblasts which are the current gold standards using maltose, glycogen, or 4-methylumbelliferyl-alphaD-glucopyranoside (4MUG) as substrate.

Acid alpha-glucosidase, also known as acid maltase, catalyzes the hydrolysis of alpha-1,4 and 1,6-glucosidic linkages on glycogen, at acidic $\mathrm{pH}^{8}$ There are many isoenzymes of alphaglucosidase with a great deal of structural homology, which are coded for by different genes. This can confound diagnosis if 
enzyme assays with overlapping specificities, or cell types which express isoenzymes other than the one causing disease are used. The most prevalent isoenzymes include acid alpha-glucosidase, sucrase isomaltase, maltase-glucoamylase, glucosidase II, and neutral alpha-glucosidase. ${ }^{8}$ Acid alpha-glucosidase and neutral alpha-glucosidase are ubiquitous. Maltase-glucoamylase (a renal isoenzyme) is prevalent in neutrophils, but not in lymphocytes. ${ }^{9}$

With the advent of enzyme replacement therapy (ERT) as a potential treatment of Pompe disease, a quick and reliable screening assay is needed. A GAA enzyme assay in lymphocytes was evaluated for prediction of infantile Pompe disease, and compared to an established assay in cultured skin fibroblasts. Lymphocytes were used to avoid the renal isoenzyme found in neutrophils. The assay was performed at acidic $\mathrm{pH}$, to avoid measurement of neutral alpha-glucosidase, also present in neutrophils. ${ }^{10}$ In addition, acarbose, a competitive inhibitor of intestinal alpha-glucosidases (including sucrase-isomaltase) was used to minimize interference from other isoenzymes.

Fourteen patients clinically suspected of having infantile Pompe disease had GAA enzyme activity assayed in lymphocytes and cultured skin fibroblasts on a clinical basis. These patients were being screened for potential enrollment in openlabel clinical trials exploring the safety and efficacy of Chinese hamster ovary $(\mathrm{CHO})$ cell derived recombinant human acid alpha-glucosidase (rhGAA) ERT. Inclusion criteria included a confirmed diagnosis of Pompe disease with an endogenous GAA activity of $<1 \%$ of the normal mean in skin fibroblasts. Skin fibroblast samples were assayed for GAA activity at Duke University Medical Center. GAA activity was assessed by measurement of 4-methyl-umbelliferyl- $\alpha$-D-pyranoside cleavage at $\mathrm{pH}$ 4.3. Lymphocyte assays, performed at Children's Hospital and Regional Medical Center in Seattle, were done in order to begin the screening process rapidly for enrollment in ERT trials. All testing was performed with written informed consent obtained from each patient. Additional patient data in lymphocytes $(n=11)$ without corresponding tissue enzyme activity is also reported from patients in whom the clinical diagnosis of infantile Pompe disease was suspected.

\section{MATERIALS AND METHODS}

\section{Blood preparation}

Five to ten $\mathrm{mL}$ of blood was received in $\mathrm{ACD}$ or heparin for enzyme assay. A Ficoll preparation was performed to isolate lymphocytes from other blood cells. Isolated lymphocytes were frozen at $-20^{\circ} \mathrm{C}$ until assay. Normal laboratory volunteers and unidentified left over lymphocyte preparations from routine laboratory cell marker studies were utilized to establish a normal range $(n=30)$. Lymphocyte samples from 27 infants suspected of having infantile Pompe disease were prepared and analyzed. Sixteen of these patients also had GAA enzyme assay performed in fibroblasts or muscle. Two patients with tissue enzyme data did not have lymphocyte GAA performed with acarbose.

\section{Chemicals and reagents}

All reagents were obtained from Sigma Diagnostics (St. Louis, $\mathrm{MO}$ ) unless indicated. Substrate was $6 \mathrm{mM}$ 4-methylumbelliferone-alpha-glucopyranoside, prepared in 10\% 2-methoxyethanol (Fluka)/0.2 M phosphate citrate (PC) buffer, pH 4.3 (0.1 M citric acid, $0.2 \mathrm{M} \mathrm{Na}_{2} \mathrm{HPO}_{4}$ in DI water). PC buffer $(0.2 \mathrm{M})$ was prepared as follows: add $2.1 \mathrm{~g}$ citric acid and $2.8 \mathrm{~g} \mathrm{Na}_{2} \mathrm{HPO}_{4}$ to 80 $\mathrm{mL}$ DI water in a $100 \mathrm{~mL}$ beaker, $\mathrm{pH}$ to 4.3 , bring to a final volume of $100 \mathrm{~mL}$ with DI water in a volumetric flask. Inhibitor was acarbose (Toronto Research Chemicals); $100 \mu \mathrm{M}$ in 0.2 M PC buffer, $\mathrm{pH} 4.3$, prepared fresh daily. Glycine Carbonate (GC) buffer, $0.17 \mathrm{M}, \mathrm{pH} 10.3$ was prepared by adding $12.8 \mathrm{~g}$ glycine to $55-60 \mathrm{~g}$ of $\mathrm{Na}_{2} \mathrm{CO}_{3}$ (this assures the $\mathrm{pH}>10.1$ ) in 1 liter of DI water. Four-methylumbelliferone (4-MU) standard was purchased from Calbiochem.

\section{Lymphocyte assay conditions}

Lymphocyte pellets were thawed, diluted with water to a protein concentration of $0.4 \mu \mathrm{g} / \mathrm{uL}$, and sonicated. The reaction mixture in each tube ${ }^{11}$ consisted of $100 \mathrm{uL}$ sonicated lymphocyte sample, which corresponds to a protein concentration of $0.4 \mu \mathrm{g} / \mathrm{uL}$, or $40 \mu \mathrm{g} /$ assay, $100 \mathrm{uL}$ of $6 \mathrm{mM} 4-\mathrm{MU}$-substrate, and $20 \mathrm{uL}$ of $100 \mu \mathrm{M}$ acarbose. The concentration of acarbose used for routine assay was initially determined by incubating both lymphocytes and mixed leukocytes from a normal donor, with varying concentrations of acarbose (Fig. 1). Acarbose was prepared as a $100 \mathrm{uM} / \mathrm{L}$ solution in PC buffer, and diluted from $100 \mu \mathrm{M} / \mathrm{L}$ to $6.25 \mu \mathrm{M} / \mathrm{L}$. A constant volume of $20 \mathrm{uL}$ inhibitor was incubated in a total reaction volume of $220 \mathrm{uL}$. A concentration was chosen that inhibited activity in leukocytes until stability was achieved, without significantly inhibiting activity in a lymphocyte preparation. The final concentration used for each diagnostic assay was $9.1 \mu \mathrm{M} / \mathrm{L}$ in the reaction mixture; 20 $\mathrm{uL}$ of $100 \mu \mathrm{M} / \mathrm{L}$ acarbose.

The assay was set up for each patient sample with and without acarbose inhibitor. Two blank tubes (sufficient for the entire run), with $100 \mathrm{uL}$ water replacing the lymphocyte sonicate were incubated with and without inhibitor along with patient samples. All tubes were incubated for 1 hour at $37^{\circ} \mathrm{C}$. The reaction was stopped by the addition of $2.5 \mathrm{~mL}$ of $0.17 \mathrm{M} \mathrm{GC}$ buffer, $\mathrm{pH}$ 10.3. Lymphocyte sonicate $(100 \mathrm{uL})$ was added to each blank tube after the reaction was stopped. Fluorescence was measured on a Shimadzu spectrofluoromter. The amount of 4-MU released from substrate was equivalent to the amount of substrate metabolized.

Calibration curves were created with $4 \mathrm{MU}$ working standard diluted with GC buffer to cover a range of $0.04-11.9$ nmoles. Nanomoles $4 \mathrm{MU}$ released in the assay were calculated from a calibration curve. Enzyme activity was expressed in nmole/hour/mg protein.

\section{Skin fibroblast or muscle assay conditions}

GAA activity was measured in the tissue homogenates or skin fibroblast sonicates by conversion of the artificial substrate (4-MUG) to the fluorescent product umbelliferone at 


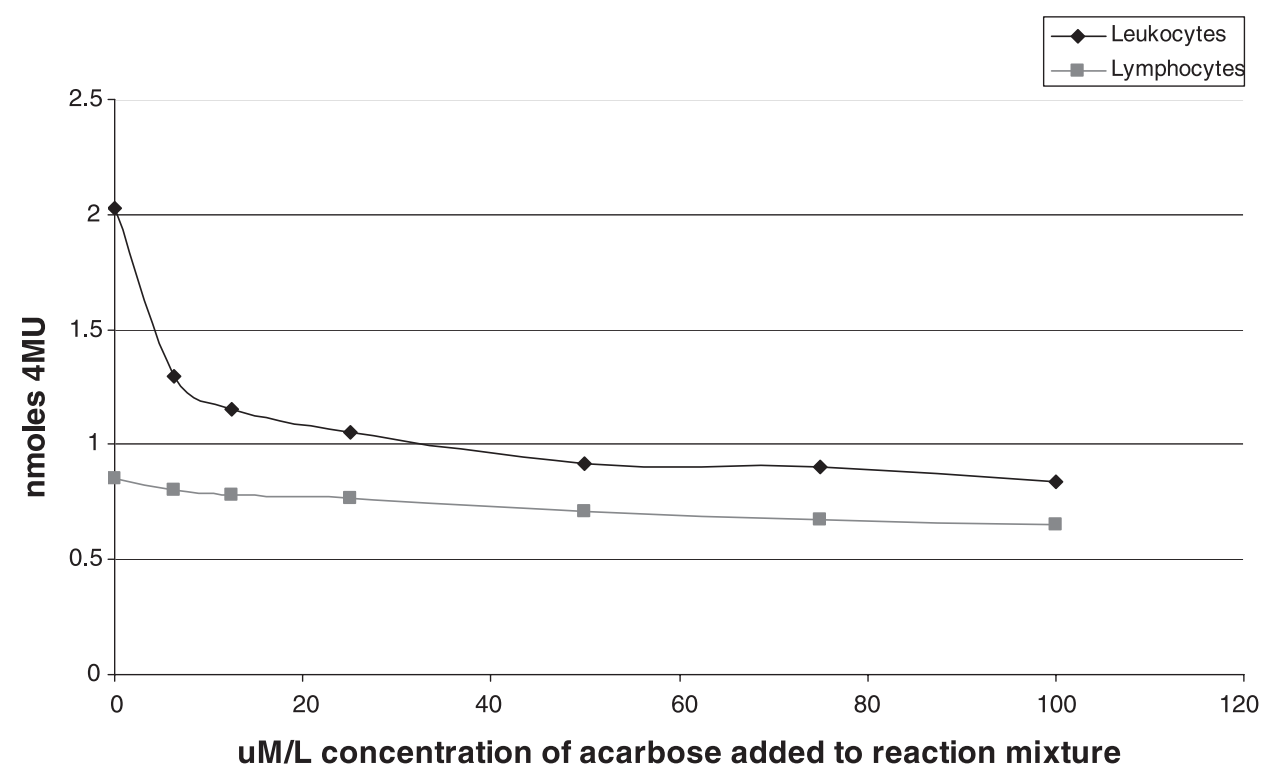

Fig. 1 Acarbose $(20 \mathrm{uL})$ was incubated in the reaction mixture $(\mathrm{TV}=220 \mathrm{uL})$ at varying concentrations to observe the increased inhibition of alpha-glucosidase with increasing concentration of acarbose. Final concentration used per assay was $9.1 \mu \mathrm{M} / \mathrm{L} ; 20 \mathrm{uL}$ of $100 \mu \mathrm{M} / \mathrm{L}$ acarbose.

acidic $\mathrm{pH} 4.3 .{ }^{12,13,14}$ The reaction was also carried out at $\mathrm{pH} 6.7$ using 4-MU for measuring the interfering cytoplasmic neutral alpha glucosidase. Acid $\beta$-galactosidase at $\mathrm{pH} 4.0$ was used as a control. Enzyme activity is expressed as nmoles/hour/mg protein.

\section{RESULTS}

\section{Normal control range}

A normal range for acid-alpha-glucosidase activity in lymphocytes with acarbose as inhibition $(n=30)$ was established as $35 \mathrm{nmole} / \mathrm{hour} / \mathrm{mg}$ protein, with a SD of 16 . Unaffected individuals ranged in activity from 26 to $81 \mathrm{nmole} /$ hour $/ \mathrm{mg}$ protein. The normal range for lymphocyte GAA activity without the addition of acarbose was $73 \mathrm{nmole} /$ hour/mg protein, with a SD of 43 . The range of activity was 33-177 nmole/ hour/mg protein. In general, use of acarbose inhibits enzyme activity by approximately $48 \%$ in isolated lymphocytes from normal individuals. The reproducibility (coefficient of variation) of this assay in a normal range was $20 \%$.

\section{Affected patient range (infantile-onset)}

Fourteen patients suspected clinically of infantile Pompe disease were tested in lymphocytes (with acarbose) at CHRMC, Seattle, WA, with parallel testing in fibroblasts or muscle performed at DUMC, Durham, NC, a laboratory with years of experience with the GAA assay (See Table 1). Lymphocyte GAA data from an additional eleven infant patients sent for routine enzyme confirmation of clinical disease are also presented. The mean enzyme activity with acarbose inhibition for affected patients was $2.4 \mathrm{nmole} /$ hour $/ \mathrm{mg}$ protein, with a SD of 2.8. GAA lymphocyte activity in patients ranged from undetectable to $7 \mathrm{nmole} / \mathrm{hour} / \mathrm{mg}$ protein, which correlates to $10 \%$ activity or less in an affected individual. The cut off for infantile
Pompe disease for lymphocyte GAA activity with acarbose was set at $<8 \mathrm{nmole} / \mathrm{mg} /$ protein or $<10 \%$ of the upper limit of normal. One patient had enzyme activity of $12 \mathrm{nmole} /$ hour $/ \mathrm{mg}$ protein, which is lower than any unaffected individual seen, but above the range established for diagnosis of disease. All fourteen patients with tissue available for correlation were clearly enzyme deficient in fibroblasts or muscle (Table 1). The GAA activity measured in lymphocytes of affected patients without acarbose shows an overlap with the range seen in normal individuals, which would result in calling approximately $50 \%$ of affected patients normal (Fig. 2). Two patients with Pompe disease listed in Table 1 did have deficient GAA enzyme activity without acarbose, but the sample was insufficient to run with inhibitor (patients 5 and 7).

\section{DISCUSSION}

Recent clinical trials of ERT with recombinant human acid alpha glucosidase (rhGAA) from transgenic or Chinese hamster ovary $(\mathrm{CHO})$ cell lines have been promising; ERT has been well tolerated in infants without serious adverse affects. ${ }^{15}$ Clinical improvement has been observed in cardiac size and function, motor function, ventilator dependence, and survival. $4,16,17,18,19,20$ For the first time there is hope for patients with this often fatal disease. With the likelihood of ERT becoming available in the near future and other therapies on the horizon, early disease recognition is of paramount importance to enable patients to receive treatment as early as possible. In infants, this recognition is critical, as the available window of time for treatment after diagnosis is extremely short. Two recent studies have concluded that the natural history of infantile Pompe disease has changed little since its original description, with death prior to the first year of life. ${ }^{4,5}$ The median age at diagnosis in these studies 
Table 1

Tissue alpha-glucosidase activity compared with lymphocyte activity with and without acarbose inhibition in patients affected with infantile Pompe disease

\begin{tabular}{|c|c|c|c|}
\hline & \multirow{2}{*}{$\begin{array}{c}\text { Tissue activity } \\
\text { nmol/hr/mg protein }{ }^{\mathrm{b}}\end{array}$} & \multicolumn{2}{|c|}{ Lymphocyte activity $^{\mathrm{a}}$} \\
\hline & & (no inhibitor) & $\begin{array}{l}\text { with acarbose } \\
\text { inhibition }\end{array}$ \\
\hline 1 & 0.93 & 70 & 7 \\
\hline 2 & 1.04 & 0 & 1 \\
\hline 3 & 0.82 & 4 & 0 \\
\hline 4 & 1.27 & 30 & 12 \\
\hline 5 & 1.54 & 7 & ND \\
\hline 6 & 0.83 & 3 & 1 \\
\hline 7 & 0.73 & 4 & ND \\
\hline 8 & 1.91 & 13 & 2 \\
\hline 9 & 0.82 & 0 & 0 \\
\hline 10 & 1.07 & 9 & 1 \\
\hline 11 & $0^{c}$ & 10 & 2 \\
\hline 12 & 1.16 & 7 & 1 \\
\hline 13 & 0.5 & 2 & 1 \\
\hline 14 & $0^{c}$ & 33 & 7 \\
\hline 15 & $0^{c}$ & 19 & 3 \\
\hline 16 & $0^{c}$ & 11 & 1 \\
\hline 17 & no tissue & 15 & 0 \\
\hline 18 & no tissue & 29 & 3 \\
\hline 19 & no tissue & 27 & 5 \\
\hline 20 & no tissue & 15 & 4 \\
\hline 21 & no tissue & 19 & 3 \\
\hline 22 & no tissue & 22 & 3 \\
\hline 23 & no tissue & 6 & 1 \\
\hline 24 & no tissue & 2 & 0 \\
\hline 25 & no tissue & 9 & 0 \\
\hline 26 & no tissue & 8 & 2 \\
\hline \multirow[t]{4}{*}{27} & no tissue & 4 & 0 \\
\hline & Mean activity, affected & 14 & 2.4 \\
\hline & SD, affected & 14.45 & 2.79 \\
\hline & Range of activity & $0-70$ & $0-12$ \\
\hline
\end{tabular}

${ }^{a}$, nmole/hr/mg protein.

${ }^{b}$, fibroblast normal activity $=260 \pm 82.2$.

${ }^{c}$, muscle normal activity $=23.9 \pm 8.6$.

$\mathrm{ND}$, not done; SD, standard deviation.

ranged from 4.5-5.3 months, with the median age of death from 6 to 8.7 months.

Lymphocyte testing offers a clear time advantage over fibroblast or muscle assays, since testing can be performed immediately after lymphocyte preparation. The disadvantage of the widely accepted skin fibroblast assay is the time needed for fibroblasts to grow to confluency in culture (four to six weeks). The major disadvantage of a muscle biopsy for muscle assay is the high anesthesia risk in patients with Pompe disease. ${ }^{21}$ While a blood draw is less invasive than a biopsy, the volume of blood needed $(10 \mathrm{~mL})$ can be significant in a low weight infant. Concerns about ambiguous results following blood transfusion are also valid, and should be considered when interpreting GAA activity in lymphocytes that fall between a normal and affected range. Lymphocyte activity without acarbose inhibition is unreliable, and can result in missed diagnosis.

The concept of isoenzyme inhibition has been used by others, specifically with newborn screening applications. Chamoles et $\mathrm{al}^{22}$ reported the use of maltose as an inhibitor to measure GAA in blood spots. Li et $\mathrm{al}^{23}$ have previously reported the use of acarbose for isoenzyme inhibition in blood spots in a GAA assay developed for tandem mass spectrometry. Similar inhibition of acid alpha-glucosidase in polymorphonuclear cell lysates was observed. Immunological capture and quantitation of enzyme activity is another approach to more specific GAA measurement in blood. ${ }^{24}$

While infantile Pompe disease is characterized by a complete absence of enzyme activity, late-onset patients may display partial activity. The level of acarbose inhibition of GAA may show overlap with normal individuals in patients with late-onset Pompe disease. When enzyme activity is indeterminate, looking at the percent inhibition accomplished by the acarbose is helpful in distinguishing normal from affected individuals. Normal individuals show a mean of $48 \%$ activity reduction with the addition of acarbose as inhibitor. Patients with infantile Pompe disease show approximately $83 \%$ inhibition with the addition of acarbose.

Lymphocyte enzyme activity without acarbose inhibition in affected individuals is variable, and as can be seen in Table 1, approximately $50 \%$ of the patients tested would be misclassified without acarbose inhibition. When lymphocytes are isolated immediately from fresh blood, the lymphocyte yield with Ficoll is higher, and the enzyme assay without acarbose inhibition is more likely to accurately reflect disease status. Cell counts on lymphocytes prepared from fresh blood averaged 90-99\% lymphocytes. Delays in processing and contamination with polymorphonuclear cells may contribute to higher activity seen with enzyme assay without acarbose. Cell counts on representative samples prepared with Ficoll 24 hours or later after the blood draw generally reflect reduced purity in the lymphocyte population with a broad range of purity $(28-81 \%$ lymphocytes, with a mean of $48 \%$ ). Demonstration of deficient enzyme levels in patient blood prepared after 24 hours indicates that acarbose successfully inhibits isoenzymes found in neutrophils so that this degree of neutrophil caontamination does not affect results. Since the GAA assay with acarbose has successfully been performed in blood spots, ${ }^{23}$ it is likely that the GAA assay with acarbose would successfully detect disease in a mixed white cell sample as well. We have been unable to validate this thoroughly by preparing and testing cells from a Ficoll lymphocyte prep and a total white cell prep, since insuf- 

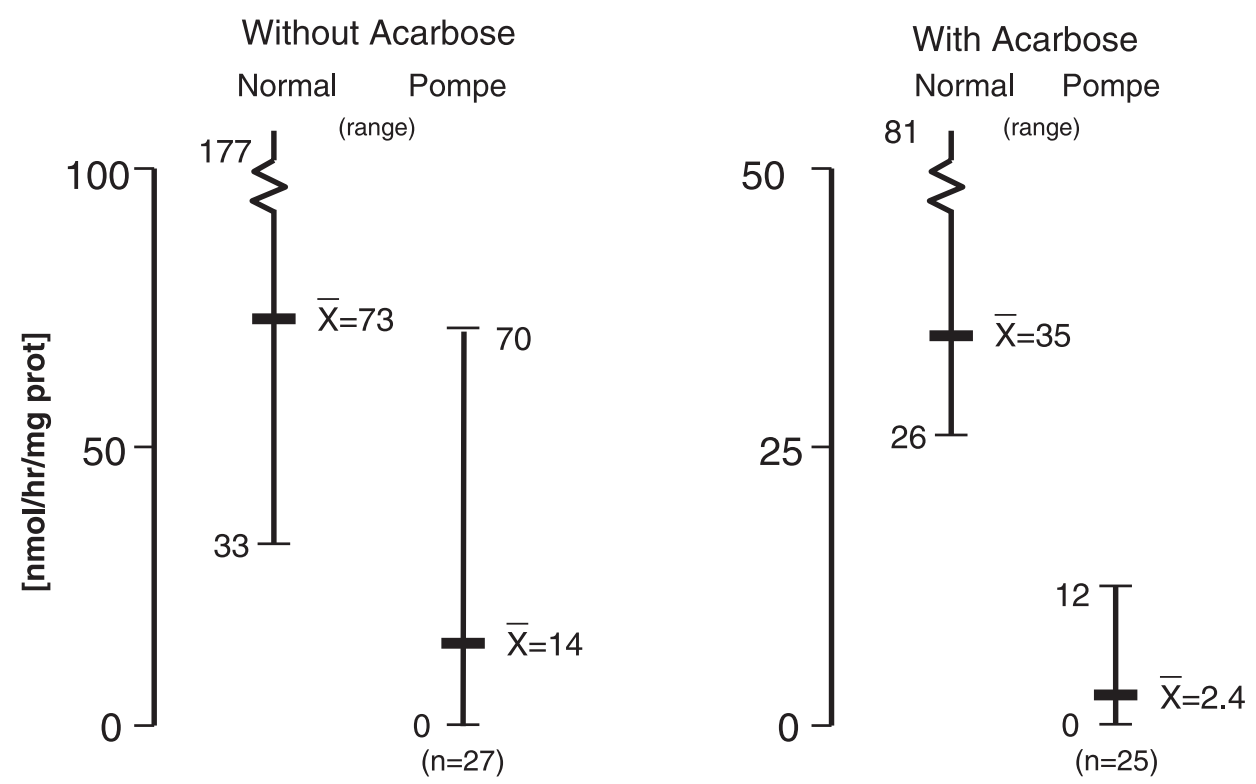

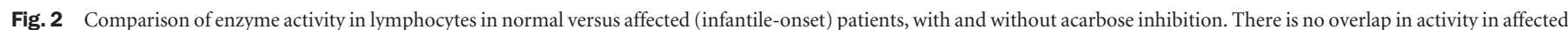
and unaffected patients when acarbose inhibition is used.

ficient sample has been available to prepare two different white cell preps in affected patients.

All patients with infantile onset, with the exception of patient \#4, would be accurately assessed as affected with the acarbose inhibition. Patient \#4, with an activity of $12 \mathrm{nmole} /$ hour/mg protein, has lower activity than has been seen in an unaffected individual, however. In addition, the $60 \%$ reduction in activity was higher than seen in an unaffected individual. This patient would not be interpreted as normal, but would require confirmation of disease in cultured fibroblasts or muscle. Since enzyme activity in fibroblasts from this patient was $<1 \%$ of the normal mean, it is unlikely that higher enzyme activity in lymphocytes accurately reflects a degree of residual enzyme activity. Residual enzyme activity and projection of a milder phenotype cannot be determined by the lymphocyte assay.

Caution should be used in interpreting lymphocyte enzyme activity in late-onset patients until more data has been collected. We have documented deficient lymphocyte enzyme activity in five patients with late-onset disease (data not presented), however, a study on a larger number of late-onset Pompe patients and comparison of tissue and lymphocyte activity needs to be done before utilizing lymphocyte activity alone for late-onset diagnosis. Furthermore, gene sequencing for causative mutations is recommended in cases where the diagnosis is in question. Overlap of GAA activity in fibroblasts can be seen between some late-onset patients and the normal unaffected control range, which could potentially result in misdiagnosis. Clinical correlation with laboratory findings (enzyme activity and mutation analysis) is very important in such instructive cases. We do not know the range of lymphocyte GAA/acarbose enzyme distribution expected in late-onset patients at this time; caution must be taken when interpreting these results.

We consider the lymphocyte assay with acarbose to be a valuable diagnostic tool, but do not anticipate that we will be able to accurately assess degree of partial enzyme activity remaining or predict phenotype. The overall sensitivity of the lymphocyte assay in infantile onset Pompe disease with acarbose is $92.8 \%$ with a specificity of $100 \%$. The positive predictive value of the test is $100 \%$; patients with $<10 \%$ enzyme activity all had clinical disease.

\section{ACKNOWLEDGMENTS}

This study was supported in part by Genzyme Corporation, Cambridge, MA. The authors would like to acknowledge Deyanira Corzo, MD, Genzyme Corporation, for helpful comments and guidance.

\section{References}

1. Hirschhorn R, Reuser AJ. Glycogen storage disease type II: Acid alpha-glucosidase (acid maltase) deficiency. In: The Metabolic and Molecular Basis of Inherited Disease, $8^{\text {th }}$ edition. Scriver CR, Beaudet AL, Sly WS, Valle D (Eds). New York: McGraw-Hill 2001:3389-3420.

2. Kishnani P, Howell R. Pompe disease in infants and children. J Pediatr 2004;144: S35-S43.

3. Marsden D. Infantile Pompe disease: A report of physician narratives from an epidemiologic study. Genet Med 2005;7:147-150.

4. Kishnani P, Hwu W, Mandel H, Nicolino M, et al. On behalf of the infantile-onset Pompe disease natural history study group; a retrospective, multinational, multicenter study on the natural history of infantile-onset Pompe disease. J Pediatr (in press).

5. Van den Hout HM, Hop W, van Diggelen OP, Smeitink JA, et al. The natural course of infantile Pompe's disease: 20 original cases compared with 133 cases from the literature. Pediatrics 2003;112:332-340.

6. Martiniuk F, Chen A, Mack A, Arvanitopoulos E, et al.Carrier frequency for glycogen storage disease type II in New York and estimates of affected individuals born with the disease. Am J Med Genet 1998;79:69-72.

7. Ausems MG, Verbiest J, Hermans MP, Kroos MA, et al. Frequency of glycogen storage disease type II in The Netherlands: implications for diagnosis and genetic counseling. Eur J Hum Genet 1999;7:713-716.

8. Taniguchi N, Kato E, Yoshida H, Iwaki S, et al. Alpha-glucosidase activity in human leucocytes: choice of lymphocytes for the diagnosis of Pompe's disease and the carrier state. Clin Chim Acta 1978;89:293-299.

9. Dreyfus J, Poenaru L. White blood cells and the diagnosis of alpha-glucosidase deficiency. Pediatr Res 1980;14:342-344. 
10. Lavrenova T, Presnova V. Rat liver neutral alpha-glucosidase: isolation and characterization. Biochem Mol Biol Int 1994;32:671-679.

11. Shapira E, Blitzer M, Miller J, Africk D. Biochem Genet, A Laboratory Manual. New York:Oxford University Press;1989;26.

12. Reuser AJ, Koster JF, Hoogeveen A, Galjaard H. Biochemical, immunological, and cell genetic studies in glycogenosis type II. Am J Hum Genet 1978;30:132-143.

13. Hermans MM, Kroos MA, van Beeumen J, Oostra BA et al. Human lysosomal alpha-glucosidase: Characterization of a catalytic site. J Biol Chem 1991;266:1350713512 .

14. Van Hove JL, Yang HW, Wu JY, Brady RO, et al. High level production of recombinant human lysosomal acid alpha-glucosidase in Chinese hamster ovary cells which targets to heart muscle and corrects glycogen accumulation in fibroblasts from patients with Pompe disease. Proc Natl Acad Sci U S A 1996;93:65-70.

15. Desnick RJ. Enzyme replacement and enhancement therapies for lysosomal diseases. J Inherit Metab Dis 2004;27:385-410.

16. Klinge L, Straub V, Neudorf U, Voit T. Enzyme replacement therapy in classical infantile Pompe disease: results of a ten month follow up study. Neuropediatrics 2005;36:6-11.

17. Amalfitano A, Bengur AR, Morse RP, Majure JM. Recombinant human acid (alpha)-glucosidase enzyme therapy for infantile glycogen storage disease type II: Results of a phase I/II clinical trial. Genet Med 2001;3:132-138.
18. Van den Hout H, Reuser AJ, Vulto AG, Loonen MC, et al. Recombinant human alpha-glucosidase from rabbit milk in Pompe patients. Lancet 2000;356:397-398.

19. Van den Hout JM, Reuser AJ, de Klerk JB, Arts WF, et al. Enzyme therapy for Pompe disease with recombinant human alpha-glucosidase from rabbit milk. J Inherit Metab Dis 2001;24:266-274.

20. Kishnani PS, Nicolino M, Rogers RC, Tsai ACH, et al. Results from a phase II trial of Chinese hamster ovary cell-derived recombinant human acid $\alpha$-glucosidase in infantile-onset Pompe disease. J Pediatr (in press).

21. Ing RJ, Cook DR, Bengur RA, Williams EA, et al. Anaesthetic management of infants with glycogen storage disease type II: a physiological approach. Paediatr Anaesth 2004;14:514-519.

22. Chamoles NA, Niizawa G, Blanco M, Gaggioli D, et al. Glycogen storage disease type II: enzymatic screening in dried blood spots on filter paper. Clin Chim Acta 2004, 347:97-102.

23. Li Y, Scott CR, Chamoles NA, Ghavami A, et al. Direct multiplex assay of lysosomal enzymes in dried blood spots for newborn screening. Clin Chem 2004;50:17851796.

24. Umapathysivam K, Whittle AM, Ranieri E, Bindloss C, et al. Determination of acid (alpha)-glucosidase protein: evaluation as a screening marker for Pompe disease and other lysosomal storage disorders. Clin Chem 2000;46:1318-1325. 